\title{
Artículos de investigación sobre comunicación y cultura en torno a Baja California, 1976-2007. Un compendio razonado
}

\begin{abstract}
Fernando Vizcarra*
Resumen. Se presenta en este trabajo un recuento sistematizado de aquellos artículos publicados en revistas arbitradas de investigación, nacionales e internacionales, cuyos contenidos abordan la comunicación y la cultura con relación al ámbito bajacaliforniano. Inicia este ensayo con un breve panorama sobre el desarrollo del campo académico de la comunicación en la entidad y continúa con el análisis descriptivo derivado de un ejercicio de sistematización de las referencias hemerográficas.

Palabras clave: Baja California, comunicación, campo académico, revistas de investigación.

Abstract. This work presents a systematized count of those articles published in peer-reviewed academic journals in Mexico and abroad, which contents refer to issues of communication and culture concerning Baja California. The essay begins showing an overview on the development of communication studies in the region and then moves on to elaborate a descriptive analysis to organize and categorize the hemerographic references.

Keywords: Baja California, communication, academic field, research journal
\end{abstract}

* Investigador del Centro de Investigaciones Culturales-Museo de la Universidad Autónoma de Baja California. Correo electrónico: fernandovizcarra@hotmail.com 


\section{Introducción}

Este trabajo tiene como antecedente los resultados de un ejercicio de sistematización documental y de análisis descriptivo sobre el conocimiento, tanto académico como no especializado, producido en torno a los ámbitos de la comunicación en nuestro estado. Ese primer proyecto, de tipo exploratorio, denominado Estudios sobre comunicación en Baja California. Referencias documentales, 1943-2006 (Vizcarra, 2006; 2007), se propuso registrar y catalogar los escritos que abordan la problemática comunicacional, en su sentido amplio, relacionada en alguna medida con el entorno bajacaliforniano. Lo anterior, con el objetivo de dar cuenta del camino avanzado y, asimismo, sugerir algunos escenarios y trayectorias posibles para los proyectos de investigación y análisis que se desarrollan en nuestro campo. Por su parte, el presente compendio busca actualizar y delimitar dicho universo documental al ámbito exclusivo de las revistas de investigación arbitradas, a fin de profundizar en el análisis descriptivo de la producción sociocientífica sobre comunicación y cultura en la entidad, a la luz del debate actual sobre las temáticas y los enfoques desarrollados en el escenario académico mexicano y latinoamericano. ${ }^{1}$

¿Bajo qué premisas y enfoques se ha constituido la comunidad académica de la comunicación en nuestro estado, a partir de los últimos 20 años? ¿Cuáles han sido sus preocupaciones docentes e investigativas? ¿Bajo qué condiciones institucionales se ha desarrollado? ¿Cómo se ha organizado nuestro pensamiento comunicacional en relación con determinados paradigmas, modelos y objetos de estudio, de acuerdo al contexto nacional e internacional? ¿Cuál es el estado actual de dicha esfera y sus trayectorias posibles? Este catálogo razonado busca aportar algunos datos y argumentos para responder estas interrogantes, por lo menos de manera tangencial. Precisamente, porque a través de los artículos publicados en revistas arbitradas se puede observar el desarrollo de ciertos contornos del campo académico de la comunica-

\footnotetext{
${ }^{1}$ Agradezco a Carmina Ortiz Márquez y a Ismael de la Torre, estudiantes de Comunicación de la UABC en Mexicali, su entusiasta colaboración en las diferentes etapas de este proyecto.
} 
ción en la entidad. No todos, por supuesto, pero sí una parte significativa que nos permite vislumbrar algunas tendencias, perfiles y rumbos de la actividad investigativa.

\section{Criterios de selección y fuentes de consulta}

Se reunieron en este compendio crítico, referencias de artículos arbitrados que abordan algún aspecto de la comunicación y la cultura con relación al entorno bajacaliforniano. Estos textos fueron publicados en revistas de investigación, impresas y electrónicas, editadas tanto en México como en el extranjero. Se incluyeron, asimismo, artículos de investigación publicados por autores (no necesariamente nacidos en Baja California) que desarrollan algún tópico de la comunicación en su dimensión local y global, y cuya presencia en la entidad ha sido determinante para la constitución de este campo académico. En relación con estos autores, se incluyeron únicamente aquellos artículos que fueron producidos en el estado, o concebidos y madurados durante su estancia en Baja California. Tales son los casos de José Carlos Lozano (Tecnológico de Monterrey) y Jesús Becerra Villegas (Universidad Autónoma de Zacatecas), pioneros de nuestro campo académico, y cuya hemerografía es más vasta que la considerada para el presente ensayo.

Sin duda, la pulverización de las fronteras disciplinarias y la fragmentación de las áreas de conocimiento representan un desafío para cualquier ejercicio de delimitación de lo comunicacional. Las referencias hemerográficas aquí seleccionadas abordan la comunicación como objeto de investigación y análisis sociocientífico. Es decir, se integran aquellos artículos arbitrados que atienden la comunicación como objeto, categoría y proceso, también los que tratan las distintas problemáticas de los medios y las mediaciones, los procesos de producción de sentido y de intercambio simbólico, los lenguajes y las discursividades, las representaciones sociales, la comunicación y sus dominios económicos, políticos y culturales, los sujetos de la comunicación, la construcción y desarrollo del propio campo académico, y otros temas pertinentes para nuestra tradición académica.

A fin de identificar en revistas de investigación, nacionales e internacionales, un acervo de artículos arbitrados sobre comunicación y 
cultura en torno a Baja California, se consultaron las bibliotecas de la Universidad Autónoma de Baja California, en Mexicali y Tijuana, y de la Universidad Iberoamericana y El Colegio de la Frontera Norte, ambas en Tijuana. Se exploró también el catálogo actualizado del Centro de Documentación CONEICC (www.coneicc.org.mx), y los inventarios sistematizados de Raúl Fuentes Navarro $(1987,1996,2003)$ y de Enrique Sánchez Ruiz (1992). Asimismo, se recorrieron los sitios web de la Red de Revistas Científicas de América Latina y el Caribe, España y Portugal REDALYC de la Universidad Autónoma del Estado de México (www.redalyc.org), de Citas Latinoamericanas en Ciencias Sociales y Humanidades CLASE de la UNAM (www.dgbiblio.unam.mx/clase.html), de Latin American Research Review de la Universidad de Texas (http:// lanic.utexas.edu), y de Journal Storage Jstor (www.jstor.org). Además, se solicitó por escrito a un grupo importante de profesores e investigadores de la entidad sus referencias documentales y posibles contactos con otros informantes. En la búsqueda exhaustiva que permitiese sustentar un balance confiable, tal vez se omitieron algunos artículos que no estuvieron a nuestro alcance. No obstante, creemos que el diagnóstico que se ha obtenido puede ser de utilidad para diversos propósitos docentes, investigativos y profesionales.

\section{Campo académico y producción de conocimiento}

A lo largo de los últimos 45 años, las llamadas "ciencias de la comunicación" se fueron configurando como una plataforma de preguntas y problemas de investigación acerca de los procesos de producción de mensajes, de las interacciones sociales y simbólicas, de los contenidos mediáticos y sus efectos en el comportamiento de las audiencias. Los insumos teóricos y metodológicos, pertenecientes a la sociología, la psicología social, la lingüística, la semiótica y la ciencia política, entre otras disciplinas, contribuyeron a la delimitación de un saber sociocientífico en torno a los procesos y fenómenos comunicacionales: la producción de sentido, el discurso, los medios y las mediaciones, la apropiación de los símbolos y la construcción identitaria. En el ámbito específico de la enseñanza, las escuelas de comunicación en México fueron integrando, durante las últimas cinco décadas, las cuatro ten- 


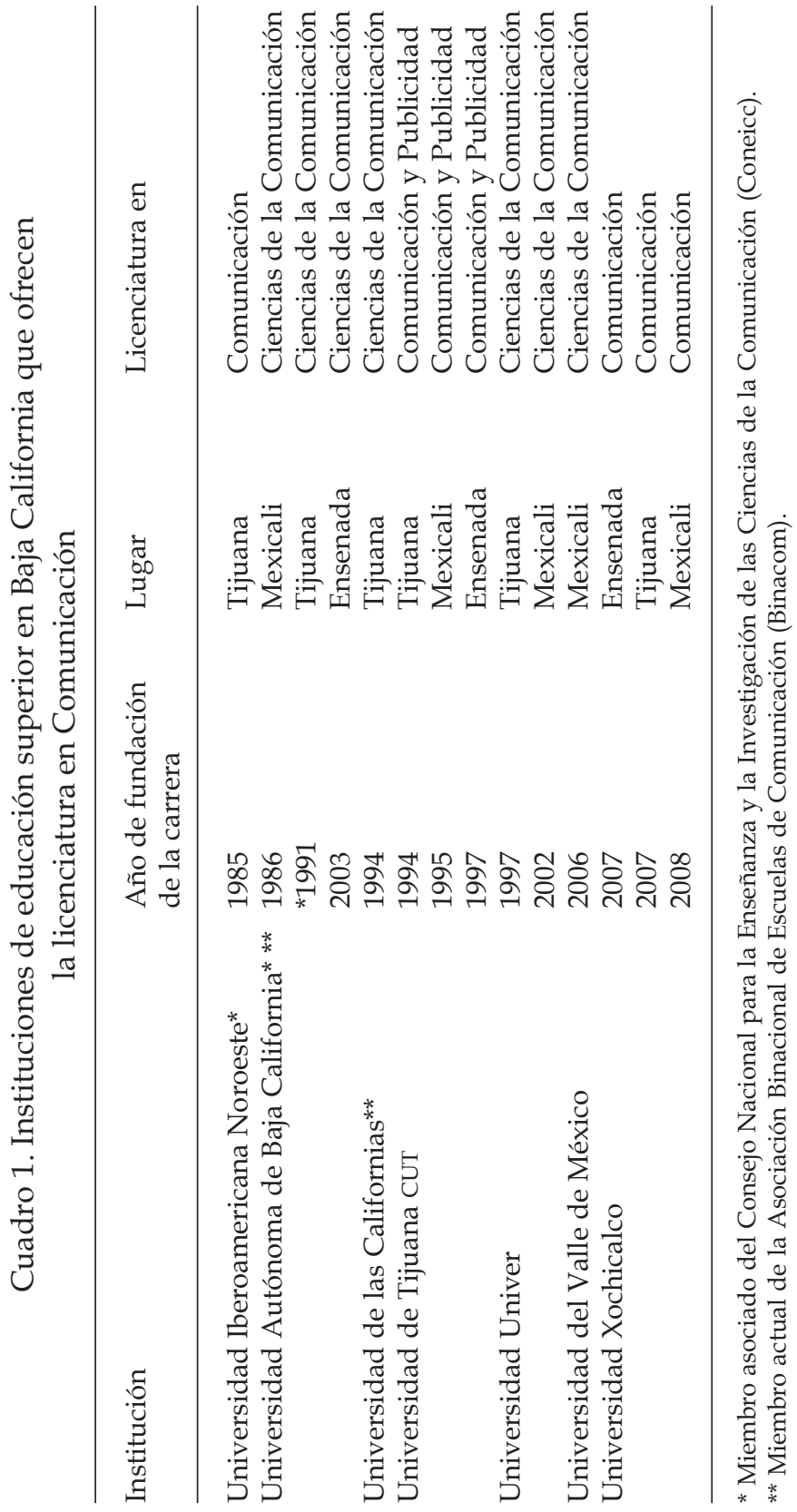


dencias principales en la formación de comunicadores: 1) periodistas e informadores; 2) humanistas y divulgadores de la cultura; 3) científicos y analistas sociales, y 4) publicistas y comunicadores organizacionales. Estas cuatro identidades profesionales no sólo se fusionaron en los planes de estudio de las carreras de comunicación en la entidad, con sus diferentes énfasis, tensiones y dispersiones, sino también determinaron las agendas de investigación y análisis de la comunicación a escala regional.

Aunque la experiencia bajacaliforniana acogió gran parte de las pautas académicas del entorno nacional y latinoamericano durante la década de los ochenta, periodo en que surgen las primeras escuelas de comunicación en el estado (véase cuadro 1), sus características locales, tanto institucionales como individuales, fueron modelando los rasgos específicos de este escenario en la entidad. Algunas de estas pautas y características pueden observarse en el cuadro 2, donde se propone un itinerario general de la composición del campo académico de la comunicación en Baja California, dividido en lustros. El primero, de 1985 a 1989, se distingue por la aparición de las primeras licenciaturas: la Universidad Iberoamericana, Campus Tijuana, y la Universidad Autónoma de Baja California, en Mexicali (véase cuadro 2). Es una tierra casi baldía, donde los escasos licenciados en Comunicación, egresados del Tecnológico de Monterrey, la UIA de la ciudad de México, la UAM-Xochimilco, la UNAM, o el ITESO, no tienen problemas para dedicar algunas horas de su práctica profesional a la docencia universitaria. Son escasas las plazas para profesores de tiempo completo y la investigación; aunque forma parte de la retórica institucional, es una actividad definida por el voluntarismo de cada docente. En las escuelas donde se ofrece esta licenciatura no hay condiciones institucionales para la investigación formal. Los profesores no tienen posgrados y, salvo algún programa de El Colegio de la Frontera Norte, no hay maestrías ni doctorados en las áreas de ciencias sociales y humanidades.

En estos primeros años, 1985-1989, se sigue leyendo en las escuelas a los autores anglosajones de la tradición funcionalista: Paul Lazarfeld, Wilbur Schramm, David K. Berlo, Harold Laswell, Robert Merton, Frazer Bond y otros. Pero también a los filósofos de la Escuela de 


\section{Cuadro 2. Tendencias y rasgos de composición del campo académico de la Comunicación en Baja California}

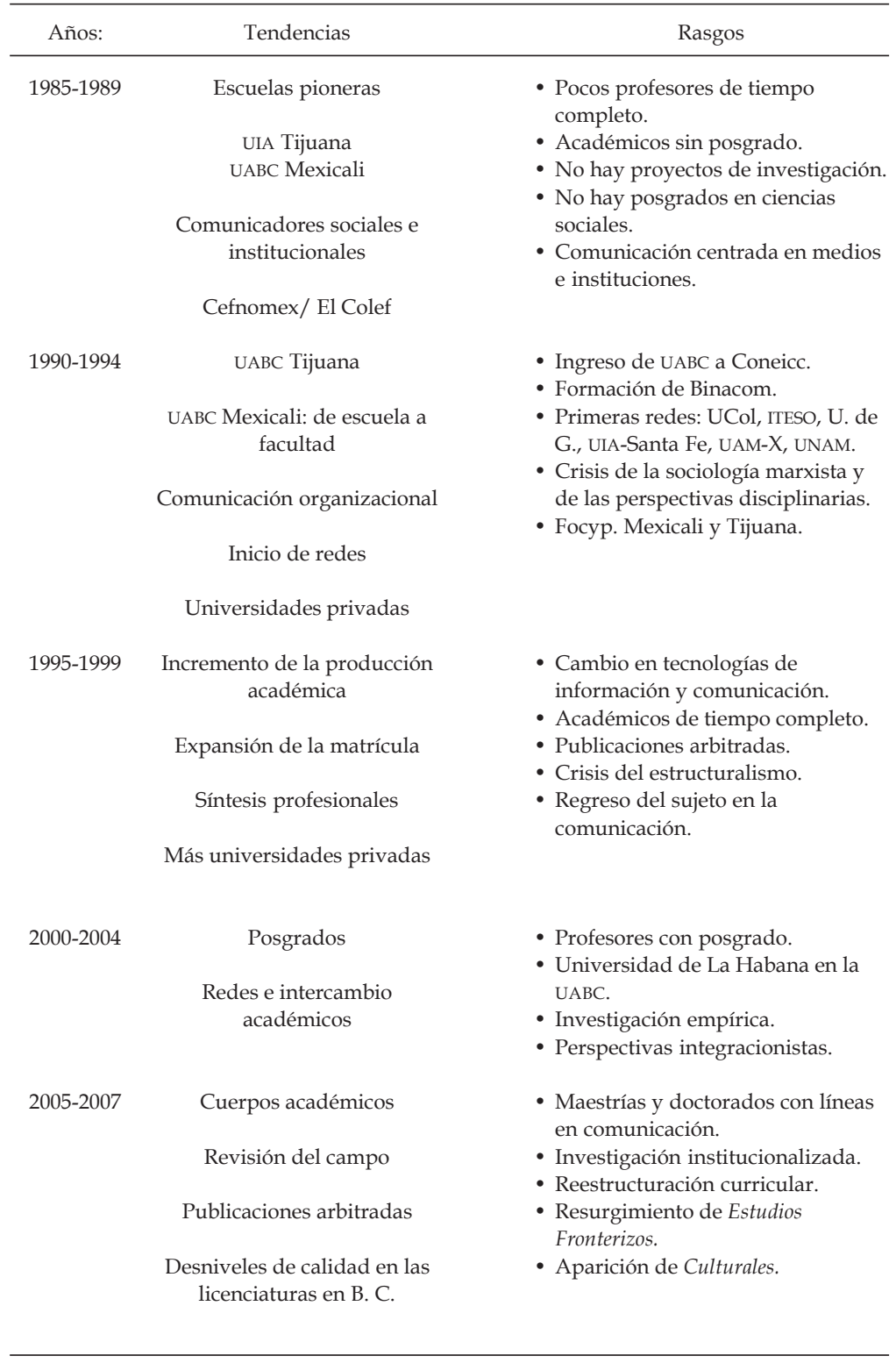


Frankfurt y otros pensadores provenientes de la sociología crítica: Antonio Gramsci, Louis Althusser, Michel Foucault, Pierre Bourdieu, Michel de Certeau y demás. En la mayoría de los planes de estudios, la semiótica se aborda como asignatura independiente de las teorías y las metodologías; Ferdinand de Saussure, Pierre Giraud, Umberto Eco, Roland Barthes, A. J. Greimas, Marshall Mc Luhan y Yuri Lotman son los más consultados. Igualmente, se atienden las perspectivas de la economía política de la comunicación y la cultura: Herbert Schiller, Graham Murdock, Daniel Bell y Armand Mattelart, entre otros. Los investigadores mexicanos e hispanoamericanos también aparecen en la bibliografía de los cursos teóricos y metodológicos: Javier Esteinou, Enrique Sánchez Ruiz, Fátima Fernández, Gilberto Giménez, Jesús Martín Barbero, José Márquez de Melo, Luis Ramiro Beltrán, Antonio Pasquali, Aníbal Ford, Daniel Prieto Castillo, Manuel Martín Serrano y demás. Es una etapa en la que se discute sobre las industrias culturales, las lógicas de producción y distribución de los contenidos mediáticos, los discursos, las mediaciones y las identidades culturales. Sin embargo, en este primer lustro hay una escasa problematización de los procesos locales.

El segundo lustro, 1990-1994, registra las primeras redes institucionales que servirán para orientar en los próximos años, con un mayor grado de información y conciencia, los planes de estudios y los programas de trabajo de cada licenciatura. La UABC y la UIA Tijuana ingresan al Consejo Nacional para la Enseñanza y la Investigación de las Ciencias de la Comunicación (Coneicc), e impulsan la formación de la Asociación Binacional de Escuelas de Comunicación (Binacom), que posteriormente vinculará a nuestras universidades con las del sur de California (San Diego State University, University of California San Diego, University of San Diego, Southwestern College, San Diego City College y otros centros de educación superior). Se desarrollan también los primeros proyectos de investigación interinstitucional con el Programa Cultura de la Universidad de Colima, que encabezan Jorge A. González y Jesús Galindo, cuyo proyecto nacional de investigación denominado La transformación de las ofertas culturales y sus públicos en México: genealogías, cartografías y prácticas culturales en el siglo XX (Focyp), dejará profunda huella en una generación de estudiantes que en la 
siguiente década serán los profesores e investigadores de la comunicación y la cultura en Baja California. En esta etapa surgen universidades privadas en todo el estado que ofrecen esta licenciatura (véase cuadro 1), y cuya expansión tanto en número de escuelas como en matrícula continuará hasta la actualidad.

Se puede afirmar que éste es un periodo de legitimación para el campo académico de la comunicación. Con cierta autonomía, se habla de la perspectiva comunicacional para delimitar ciertos objetos de estudio, y los resultados de investigaciones y análisis en esta materia son utilizados frecuentemente por diversas instituciones. Al mismo tiempo, se extiende la crisis de la sociología marxista a los diversos frentes de las ciencias sociales y las humanidades, dando paso a las postdisciplinas y a un llamado global a abrir las ciencias sociales. En las escuelas de la entidad, cada vez se consulta a más autores mexicanos e hispanoamericanos: Raúl Fuentes Navarro, Rossana Reguillo, Jorge A. González, Jesús Galindo, Guillermo Orozco, José Carlos Lozano, Néstor García Canclini, Maria Immacolata Vassallo de Lopes y otros.

El lustro 1995-1999 marca el inicio de la producción de conocimiento sistematizado y continuo en materia de comunicación en Baja California. Mediante publicaciones que registran la investigación empírica o la reflexión crítica, este campo va ampliando sus redes institucionales y va acreditando sus prácticas al interior del espacio universitario y frente a otras instituciones públicas y privadas. Se amplía el número de profesores de tiempo completo, lo que posibilita el desarrollo de proyectos académicos de mayor alcance y continuidad. Sin embargo, también comienzan a manifestarse ciertos desniveles en la calidad de la enseñanza de algunas universidades privadas emergentes. Las que registran mayores rezagos son aquellas que posponen la incorporación de profesores de tiempo completo a sus programas, las que desestiman la formación de sus recursos humanos a nivel de posgrado, las que desdeñan la vinculación y el intercambio académico, las que renuncian a los proyectos editoriales y otras iniciativas de divulgación, y se concentran únicamente en la docencia.

En cuanto a los contenidos curriculares, la tradición funcionalista en este periodo queda reducida a una historia de las teorías de la comunicación y la crisis del estructuralismo anuncia el regreso del sujeto 
en los estudios de la cultura. Se lee en las aulas a Anthony Giddens, John B. Thompson, Klaus Bruhn Jensen, Jeffrey Alexander y otros integracionistas. Igualmente a Niklas Luhmann, Giovanni Sartori, Jürgen Habermas e Immanuel Wallerstein. Pero también a un grupo de académicos mexicanos que analizan la problemática de las industrias mediáticas, las telecomunicaciones, las tecnologías y sus flujos de información, las relaciones entre política y comunicación, así como la reglamentación de los medios, desde enfoques vinculados con la economía política, la sociología y el derecho: Florence Toussaint, Delia Crovi, María de la Luz Casas, Carmen Gómez Mont, Francisco Aceves, Octavio Islas y Ernesto Villanueva, entre otros.

En los periodos comprendidos de 2000 a 2004, y de 2005 a 2007, observamos un notable crecimiento tanto cualitativo como cuantitativo del escenario académico bajacaliforniano. Se impulsan programas de posgrado pertenecientes a diversas áreas de las ciencias sociales: la Maestría en Comunicación ofrecida por la Universidad de La Habana para profesores de la UABC; la Maestría en Comunicación y Diseño de la UIA Tijuana; la Maestría en Ciencias Sociales del Instituto de Investigaciones Sociales y la Facultad de Ciencias Administrativas y Sociales de la UABC; la Maestría en Estudios y Proyectos Sociales que suscriben la Facultad de Ciencias Humanas, la Facultad de Ciencias Sociales y Políticas, y el Instituto de Investigaciones Sociales; la Maestría en Estudios Socioculturales que conjuntamente ofrecen el Centro de Investigaciones Culturales-Museo y El Colegio de la Frontera Norte; y el Doctorado en Estudios del Desarrollo Global de la Facultad de Economía de la UABC, próximamente con un área de especialización en comunicación y cultura.

Otro rasgo central de esta última etapa lo constituye la reorganización del espacio docente e investigativo a través de los cuerpos académicos que, sin duda, resultará determinante para las estrategias de consolidación de este campo en el futuro inmediato. Mientras tanto, la investigación académica se institucionaliza mediante los mecanismos de apoyo de cada universidad y por efecto de las convocatorias nacionales (Promep, Conacyt, etc.) e internacionales (Fulbright-García Robles, Guggenheim Foundation Fellowship, Rockefeller Foundation, etc.). En este contexto, resurge la revista Estudios Fronterizos y aparece 
Culturales, publicación arbitrada del CIC-Museo UABC. Junto con Frontera Norte, editada por El Colef, ambos proyectos editoriales se han convertido en el espacio académico más importante para la divulgación de las ciencias sociales y las humanidades en Baja California. Son una fuente de formación, consulta y apoyo para las actividades de docencia, investigación y reflexión de diversas problemáticas, entre ellas, la sociocultural. Pero, además, estos medios buscan constituirse como un soporte para la planeación, implementación y evaluación de políticas sociales y culturales desarrolladas en universidades, centros de investigación e instituciones públicas y privadas.

Aunado a esto, es tiempo de reestructuraciones curriculares, de revisiones de autores y obras, y de escrutinios sobre el campo y sus competencias. Manuel Castells y Armand Mattelart tienen regresos espectaculares, y sobre todo este último, se sitúa en el centro de los recuentos y balances sobre estudios de la cultura y la comunicación. Los autores que interpretan la cultura en el seno de la posmodernidad, como Michel Maffesoli, Zygmunt Bauhman y Gilles Lipovetski, resul$\tan$ muy atractivos principalmente para aquellos profesores universitarios jóvenes que crecieron en la Red, en el anime y el manga. Se lee también a Ulrich Beck, James Lull, Dominique Wolton y Alejandro Piscitelli. Asimismo, son lecturas recomendadas en el aula y entre los grupos de investigación, aquellas que abordan las relaciones entre la producción discursiva y las representaciones sociales. Aquí se inscriben los trabajos de Margarita Zires, Carmen de la Peza, Sarah Corona, Ana Uribe, Karla Covarrubias y Patricia Torres, Marta Rizo, Héctor Gómez y Tanius Karam, además de otros.

En este complejo escenario, se incorpora a la discusión académica un grupo de investigadores y profesores que laboran en universidades y centros de investigación en Baja California, y que son objeto de análisis de este ensayo. Entre ellos destacan José Manuel Valenzuela, investigador de El Colegio de la Frontera Norte, cuyo objeto de estudio son las identidades y representaciones socioculturales en la frontera México-Estados Unidos; Jesús Becerra Villegas, pionero de nuestro campo y actualmente investigador de la Universidad Autónoma de Zacatecas, quien estudia sobre todo la semiótica de la comunicación y la cultura; Norma Iglesias, cuyo proyecto de investigación sobre las 
representaciones culturales y de género en el cine y el arte fronterizos inició en El Colegio de la Frontera Norte y continúa ahora en San Diego State University; Manuel Ortiz Marín, profesor de la UABC en Mexicali y analista de las relaciones entre Estado, medios y poder político en Baja California; Luz María Ortega Villa, también adscrita a la UABC en Mexicali e investigadora de los públicos y las ofertas culturales en esta región; Maricela López Ornelas, quien desde el Instituto de Investigación y Desarrollo Educativo de la UABC en Ensenada analiza el fenómeno de la divulgación científica por medios electrónicos; David González, profesor de la UABC en Tijuana y premio nacional de tesis de maestría, quien estudia las confluencias entre los jóvenes fronterizos y los contenidos televisivos; y Ricardo Morales, académico de la Universidad Iberoamericana Tijuana, cuyo ámbito de estudio son los jóvenes, las redes sociales y la cultura urbana.

Los rasgos constituyentes del campo académico de la comunicación en Baja California, hasta aquí esbozados, con sus determinaciones nacionales e internacionales, en alguna medida se expresan a través de las temáticas, enfoques y contenidos de los artículos de investigación que en este ensayo se refieren. Es así, porque en Baja California, como en el resto del país, la elaboración de conocimiento y análisis en esta materia ha estado articulada a las escuelas de comunicación.

\section{Artículos de investigación}

La producción de saberes acerca de la comunicación y la cultura no se reduce a las publicaciones especializadas, por supuesto. Pero es a través de los artículos de investigación como se pueden obtener valiosos indicadores del grado de especialización y orientación de nuestro entorno académico. Para los objetivos de este trabajo, un artículo sociocientífico se define como un informe escrito y publicado que describe resultados originales derivados de un proceso de investigación formal, de acuerdo con las normas de presentación y edición establecidas a partir de una amplia tradición tanto metodológica como ética, que determina las formas de construcción y comunicación del conocimiento. Desde una perspectiva hermenéutica, un artículo sociocien- 
tífico es también un ejercicio de argumentación de ideas en torno a una pregunta, objetivo o planteamiento central. Se trata de una exposición reflexiva donde el autor plantea argumentos sustentados en teorías, conceptos o referentes empíricos.

Como ya se mencionó, la información hemerográfica que compone este trabajo fue tomada de un catálogo más amplio constituido por 692 referencias documentales de tipo académico, periodístico y de divulgación, además de tesis y trabajos terminales de licenciatura y posgrado, seleccionados por su formato bajo la siguiente clasificación: libros y cuadernos, capítulos de libros, conferencias y ponencias publicadas en memorias, artículos en revistas de investigación, artículos en revistas de divulgación, artículos en revistas electrónicas, artículos en revistas en línea, artículos y reportes en discos compactos, tesis y trabajos terminales de licenciatura, de maestría y de doctorado (Vizcarra, 2007). De este compendio actualizado, se eligieron para el presente análisis aquellos artículos publicados en revistas de investigación impresas y electrónicas, tanto nacionales como internacionales. Así, se obtuvo un registro de 92 artículos de investigación sobre comunicación y cultura en torno a Baja California, publicados de 1976 a 2007 (véase cuadro 3).

Cuadro 3. Artículos de investigación sobre comunicación y cultura en torno a Baja California,

por lustros

\begin{tabular}{|c|c|c|c|}
\hline Periodo & Cantidad & $\%$ del total & $\begin{array}{c}\text { Promedio de publicaciones } \\
\text { por año }\end{array}$ \\
\hline $1976-1980$ & 1 & 1.086 & 0.2 \\
\hline $1981-1985$ & 3 & 3.260 & 0.6 \\
\hline 1986-1990 & 4 & 4.347 & 0.8 \\
\hline 1991-1995 & 13 & 14.13 & 2.6 \\
\hline 1996-2000 & 22 & 23.913 & 4.4 \\
\hline 2001-2005 & 31 & 33.695 & 77.173 \% \\
\hline 2006-2007 & 18 & 19.565 & 9 \\
\hline Total & 92 & 100 & \\
\hline
\end{tabular}


Como puede observarse en este cuadro, la cantidad de artículos de investigación publicados está relacionada con la aparición y consolidación de escuelas de comunicación en la entidad y, específicamente, con la incorporación a las universidades de profesores e investigadores de tiempo completo. A partir de 1996, se registra un incremento significativo en la publicación de textos de corte sociocientífico, que continuará en aumento hasta el presente. Si las primeras licenciaturas en comunicación en el estado surgieron hace 23 años aproximadamente, es a partir de la última década cuando este espacio alcanza cierto nivel de especialización, ya que de 1996 a 2007, se publicó más del $77 \%$ de los artículos de investigación. Un proceso inducido, además, por la ampliación en la oferta de posgrados, la multiplicación de revistas impresas y electrónicas, y las pautas de evaluación y acreditación académicas que se implementan desde Conacyt, la Secretaría de Educación Pública, a través de Promep, y el programa de estímulos al personal académico denominado Ppredepa, de la UABC, principalmente.

El cuadro 4, por su parte, muestra las principales revistas de investigación donde fueron publicados estos ensayos. No es accidental que Estudios sobre las Culturas Contemporáneas, publicación semestral del Programa Cultura de la Universidad de Colima, encabece la lista junto con Razón y Palabra. Fueron Jorge González y Jesús Galindo, fundadores de este programa, quienes propusieron los primeros contactos con las carreras de comunicación de Baja California, e impulsaron desde principios de los noventa la formación de equipos de investigación entre profesores y estudiantes de la UABC y la UIA Tijuana. El Programa Cultura fue un proyecto exitoso en la formación de colectivos de investigación, integrados en su mayoría por profesores jóvenes y estudiantes que, a partir de los noventa, hicieron de ese órgano uno de sus primeros espacios de publicación. Por su parte, Razón y Palabra, revista electrónica del Tecnológico de Monterrey, Campus Estado de México, impulsada por Octavio Islas y Fernando Gutiérrez desde 1996, se ha convertido en uno de los foros más importantes de México y Latinoamérica para pensar la comunicación, y en uno de los medios que más ha divulgado el trabajo de la academia bajacaliforniana. Destaca también el Anuario de Investigación de la Comunicación Coneicc, pu- 
Cuadro 4. Artículos de investigación sobre comunicación y cultura en torno a Baja California, por revistas

Revista de investigación Cantidad \%del total

Estudios sobre las Culturas Contemporáneas

Universidad de Colima

Razón y Palabra

Instituto Tecnológico de Estudios Superiores de Monterrey, Campus Estado de México

Anuario Coneicc

Consejo Nacional para la Enseñanza

y la Investigación en Ciencias

de la Comunicación Coneicc

Estudios Fronterizos

Universidad Autónoma de Baja California

Comunicación y Sociedad

Universidad de Guadalajara

Culturales

Universidad Autónoma de Baja California

Frontera Norte

El Colegio de la Frontera Norte

Espacios de la Comunicación

Universidad Iberoamericana, Santa Fe

Texto Abierto

Universidad Iberoamericana León

Quórum Académico

Universidad del Zulia

Revista de la Educación Superior

Asociación Nacional de Universidades e Instituciones de Educación Superior

Revista Mexicana de Sociología

Universidad Nacional Autónoma de México

Aztlán: A Journal of Chicano Studies

Universidad de California, Los Ángeles

La Crítica Sociológica

SIARES/Roma

Otras 17 revistas 


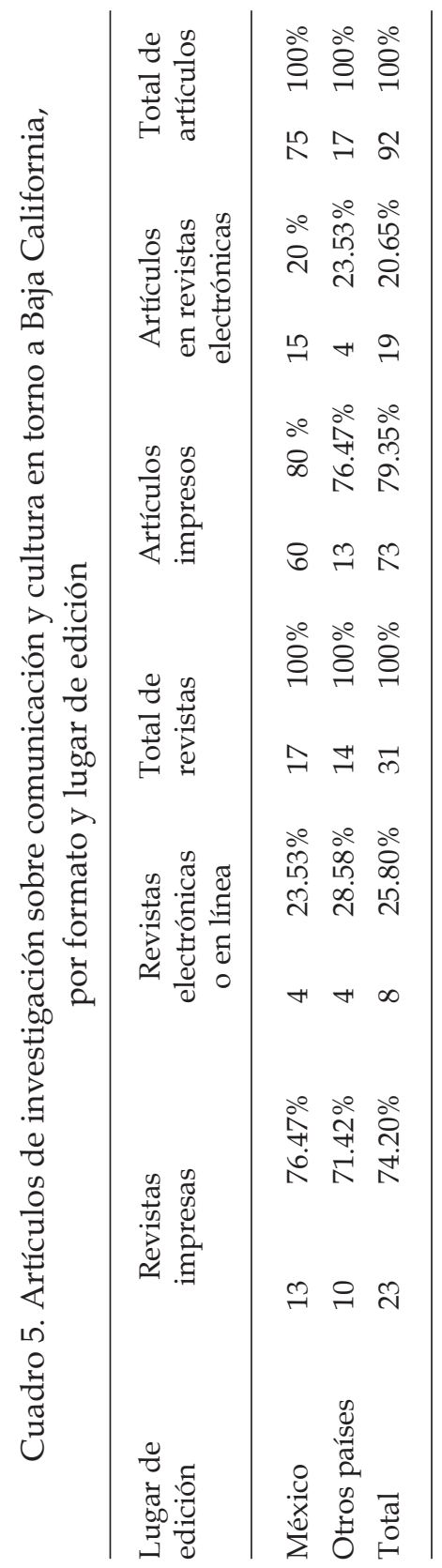


blicado desde 1994 por el Consejo Nacional para la Enseñanza y la Investigación de las Ciencias de la Comunicación. Es un proyecto de carácter interinstitucional que se ha consolidado en esta década como el referente indispensable de nuestro campo académico a nivel nacional. Estas tres publicaciones concentran el 37\% de los artículos registrados en el presente catálogo. Parece extraño que los comunicólogos de la entidad aún no hayan contemplado como espacios idóneos de publicación a Global Media Journal en Español, del Tecnológico de Monterrey, Campus Monterrey; a Versión, de la Universidad Autónoma Metropolitana-Xochimilco, y a Diálogos de la Comunicación de FALAFACS, entre otras importantes revistas.

Los cuadros 5, 6 y 7 muestran algunos indicadores sobre los lugares de edición de revistas tanto impresas como electrónicas, así como la distribución de los textos en dichos medios. En el cuadro 5 se observa un equilibrio entre el número de revistas mexicanas impresas (13) y electrónicas (4) donde se han publicado artículos en torno a Baja California y la cantidad de revistas de investigación impresas (10) y electrónicas (4) de otros países. No es así en cuanto a los artículos, que en el caso de las revistas mexicanas, impresas y electrónicas, concentran un total de 75 textos, en relación con las revistas extranjeras donde se han publicado sólo 17. Si la investigación académica en el estado es una actividad emergente, la publicación en revistas extranjeras, por su parte, está en ciernes. Respecto al lugar de edición de las revistas mexicanas, el cuadro 6 apunta hacia la ciudad de México como el primer surtidor de opciones editoriales. Son revistas de la UIA Santa Fe, El Colegio de México, la UNAM, la UAM y la ANUIES, donde se han publicado textos relacionados con la academia bajacaliforniana. Le siguen las publicaciones locales donde la UABC y El Colegio de la Frontera Norte se presentan como únicas alternativas para la divulgación de temas comunicacionales y socioculturales. De esta lista, sobreviven Culturales, indexada en la Red de Revistas Científicas de América Latina y el Caribe, España y Portugal (REDALYC), Estudios Fronterizos y Frontera Norte, estas últimas inscritas en el índice de revistas científicas mexicanas del Conacyt. Nuevo León registra dos revistas electrónicas del Tecnológico de Monterrey, que posteriormente se convirtieron en una: Global Media Journal en Español, indexada en REDALYC. Jalisco 
Cuadro 6. Artículos de investigación sobre comunicación y cultura en torno a Baja California, por lugar de edición de revistas mexicanas

\begin{tabular}{|c|c|}
\hline Revistas Mexicanas & Lugar de edición \\
\hline $\begin{array}{l}\text { Espacios de la Comunicación } \\
\text { Universidad Iberoamericana Santa Fe }\end{array}$ & \multirow{5}{*}{ Ciudad de México } \\
\hline $\begin{array}{l}\text { Estudios Sociológicos } \\
\text { El Colegio de México }\end{array}$ & \\
\hline $\begin{array}{l}\text { Revista de la Educación Superior } \\
\text { Asociación Nacional de Universidades e } \\
\text { Instituciones de Educación Superior }\end{array}$ & \\
\hline $\begin{array}{l}\text { Revista Mexicana de Sociología } \\
\text { Universidad Nacional Autónoma de México }\end{array}$ & \\
\hline $\begin{array}{l}\text { Sociológica } \\
\text { Universidad Autónoma Metropolitana }\end{array}$ & \\
\hline $\begin{array}{l}\text { Culturales } \\
\text { Universidad Autónoma de Baja California }\end{array}$ & \multirow{4}{*}{ Baja California } \\
\hline $\begin{array}{l}\text { Estudios Fronterizos } \\
\text { Universidad Autónoma de Baja California }\end{array}$ & \\
\hline $\begin{array}{l}\text { Frontera Norte } \\
\text { El Colegio de la Frontera Norte }\end{array}$ & \\
\hline $\begin{array}{l}\text { Speculum } \\
\text { Universidad Autónoma de Baja California }\end{array}$ & \\
\hline $\begin{array}{l}\text { Global Media Journal en Español } \\
\text { Instituto Tecnológico de Estudios Superiores } \\
\text { de Monterrey, Campus Monterrey }\end{array}$ & \multirow[t]{2}{*}{ Nuevo León } \\
\hline $\begin{array}{l}\text { Hipertextos } \\
\text { Instituto Tecnológico de Estudios Superiores } \\
\text { de Monterrey, Campus Monterrey }\end{array}$ & \\
\hline $\begin{array}{l}\text { Comunicación y Sociedad } \\
\text { Universidad de Guadalajara }\end{array}$ & \multirow[b]{2}{*}{ Jalisco } \\
\hline $\begin{array}{l}\text { Eslabones } \\
\text { Universidad de Guadalajara }\end{array}$ & \\
\hline
\end{tabular}




\begin{tabular}{l|l}
\hline Revistas Mexicanas & Lugar de edición \\
\hline $\begin{array}{l}\text { Estudios sobre las Culturas Contemporáneas } \\
\text { Universidad de Colima }\end{array}$ & Colima \\
\hline $\begin{array}{l}\text { Razón y Palabra } \\
\text { Instituto Tecnológico de Estudios Superiores } \\
\text { de Monterrey, Campus Estado de México }\end{array}$ & Estado de México \\
\hline $\begin{array}{l}\text { Texto Abierto } \\
\text { Universidad Iberoamericana León }\end{array}$ & Guanajuato \\
\hline $\begin{array}{l}\text { Anuario Coneicc } \\
\text { Consejo Nacional para la Enseñanza } \\
\text { y la Investigación en Ciencias de la }\end{array}$ & Varios estados \\
Comunicación & \\
\hline
\end{tabular}

aporta a este inventario dos revistas de enorme tradición. Entre éstas sobresale Comunicación y Sociedad, que ha desempeñado un papel esencial en la conformación del campo sociocientífico de la comunicación en México. La presencia de textos vinculados con Baja California en revistas de Colima (Estudios sobre las Culturas Contemporáneas), del Estado de México (Razón y Palabra) y Guanajuato (Texto Abierto), entre otras entidades, revela por una parte las configuraciones y trayectorias de las redes académicas de los bajacalifornianos $\mathrm{y}$, por otro lado, exhibe la ausencia de vínculos más estrechos con universidades y centros de investigación del noroeste: la Universidad de Sonora, El Colegio de Sonora, la Universidad Autónoma de Sinaloa y la Universidad Autónoma de Baja California Sur, por citar algunos. No se encontraron trabajos sobre esta temática en Región y Sociedad, de El Colegio de Sonora, en Estudios Sociales del CIAD, o en Arenas de la Facultad de Ciencias Sociales de la UAS.

Respecto al cuadro 7, se muestran las 14 revistas extranjeras identificadas en este compendio, así como las universidades que las auspician y el país de origen de cada título. Estados Unidos encabeza esta lista y le siguen España y Venezuela. A diferencia de los artículos diseminados en revistas mexicanas, que expresan de alguna forma la 


\section{Cuadro 7. Artículos de investigación sobre comunicación y cultura en torno a Baja California, por lugar de edición de revistas extranjeras}

\begin{tabular}{|c|c|}
\hline Revistas extranjeras & Lugar de edición \\
\hline $\begin{array}{l}\text { Aztlán: A Journal of Chicano Studies } \\
\text { University of California Los Angeles }\end{array}$ & \multirow{5}{*}{ Estados Unidos } \\
\hline $\begin{array}{l}\text { Discourses } \\
\text { Wayne State University }\end{array}$ & \\
\hline $\begin{array}{l}\text { Intercultural Communication Studies } \\
\text { University of Louisville }\end{array}$ & \\
\hline $\begin{array}{l}\text { International Journal of American Linguistics } \\
\text { University of Chicago }\end{array}$ & \\
\hline $\begin{array}{l}\text { Río Bravo, a Bilingual Journal of International Studies } \\
\text { The University of Texas-Pan American }\end{array}$ & \\
\hline $\begin{array}{l}\text { Pixel-Bit, Revista de Medios y Educación } \\
\text { Universidad de Sevilla }\end{array}$ & \multirow{3}{*}{ España } \\
\hline $\begin{array}{l}\text { Revista Latina de Comunicación Social } \\
\text { Universidad de La Laguna }\end{array}$ & \\
\hline $\begin{array}{l}\text { Zer, Revista de Estudios de Comunicación } \\
\text { Universidad del País Vasco }\end{array}$ & \\
\hline $\begin{array}{l}\text { Quórum Académico } \\
\text { Universidad del Zulia }\end{array}$ & \multirow[b]{2}{*}{ Venezuela } \\
\hline $\begin{array}{l}\text { Utopía y Praxis Latinoamericana } \\
\text { Universidad del Zulia }\end{array}$ & \\
\hline $\begin{array}{l}\text { Periferia } \\
\text { Universidad Surcolombiana }\end{array}$ & Colombia \\
\hline $\begin{array}{l}\text { Question } \\
\text { Universidad de La Plata }\end{array}$ & Argentina \\
\hline $\begin{array}{l}\text { Electronic Journal of Information Systems Evaluation } \\
\text { Academic Conferences Limited }\end{array}$ & Inglaterra \\
\hline $\begin{array}{l}\text { La Critica Sociologica } \\
\text { Fabrizio Serra Editor }\end{array}$ & Italia \\
\hline
\end{tabular}


madurez de las redes interinstitucionales (Coneicc, El Colef, OCUL, ANUIES, etc.) y de cuerpos académicos específicos, los textos en revistas foráneas revelan los alcances de las relaciones personales de cada profesor e investigador con sus homólogos de otras universidades extranjeras. De allí que estas revistas no reflejen un patrón estratégico o un programa de vinculación de cuerpos académicos internacionales. Seguramente ésta será la tarea por desarrollar en los próximos años.

El cuadro 8 presenta a aquellos profesores e investigadores asociados con el campo académico de la comunicación y la cultura en Baja California que más artículos de investigación han publicado. No es de ningún modo gratificante observar que más del $89 \%$ de los artículos registrados aquí, han sido producidos por tan sólo 13 autores. Mucho menos atestiguar que en un estado que cuenta con 14 escuelas de comunicación y un centro de investigación Conacyt, únicamente la Universidad Autónoma de Baja California, la Universidad Iberoamericana Tijuana y El Colegio de la Frontera Norte aporten conocimiento y análisis sobre este ámbito. Sin embargo, este escenario, a corto y mediano plazos, parece venturoso. El impacto de los posgrados, la formación de grupos de investigación en las facultades e institutos, la permanencia y consolidación de revistas arbitradas y, sobre todo, la necesidad de construir instituciones sociales sustentadas en la información y el conocimiento, seguramente serán factores que incrementen la productividad académica en términos de calidad y cantidad.

\section{Orientaciones temáticas y metodológicas}

En los siguientes cuadros se exponen las orientaciones temáticas y metodológicas de los 92 artículos incluidos en este trabajo. Los criterios de selección implementados en este rubro no son excluyentes, de tal forma que un texto puede tener varias orientaciones y ser admitido en varios cuadros simultáneamente. Al final de este ensayo, en el anexo, se encuentran las 92 referencias hemerográficas que aquí se examinan.

El cuadro 9 registra la cantidad de artículos referidos al propio campo académico de la comunicación. Aquí sobresalen los textos cuyos contenidos hacen énfasis en la teoría y la metodología, por encima de 


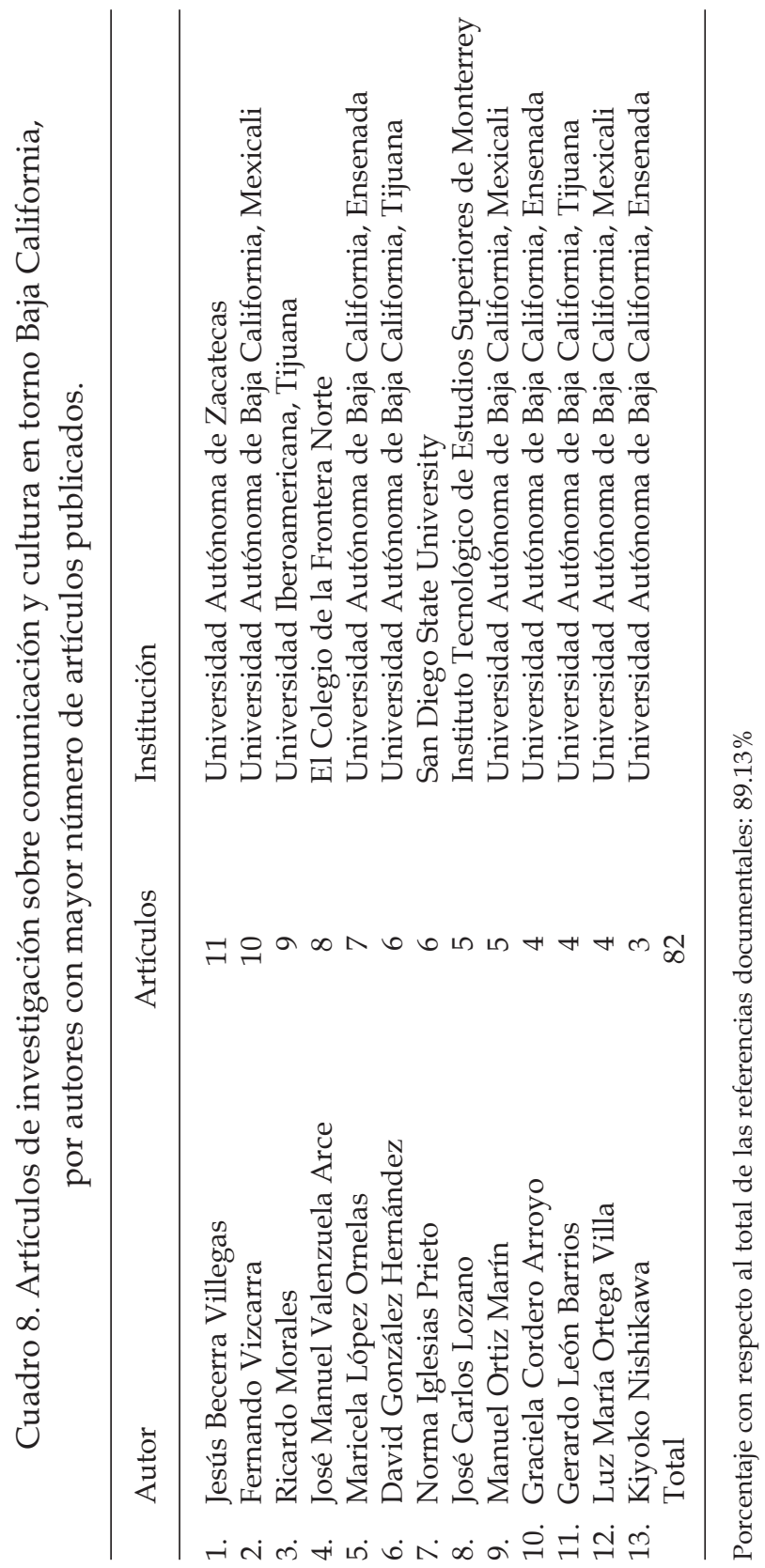


Cuadro 9. Artículos de investigación sobre comunicación y cultura en torno a Baja California, por referencia al propio campo académico (1976-2007)

\begin{tabular}{lc}
\hline Referencia & Cantidad \\
\hline Teoría y metodología & 21 \\
Tendencias de investigación y análisis & 2 \\
Diseño y evaluación curricular & 1 \\
Formación profesional & 1 \\
\hline
\end{tabular}

las tendencias de investigación y análisis, el diseño curricular y la formación profesional de los comunicólogos. Cabe mencionar que en su mayoría son ensayos que tienden a la revisión de determinados establecimientos teóricos o proponen alguna metodología o instrumento para el estudio de fenómenos comunicativos y socioculturales específicos.

Aquellos ensayos que hacen referencia a los medios de comunicación y la comunicación masiva, se agrupan en el cuadro 10. Si bien se ha llegado al consenso de que la comunicación no se agota en los medios, éstos continúan teniendo una presencia dominante en las agendas de investigación y análisis. Son el referente de los procesos socioculturales emergentes vinculados con la globalización y los efectos radicalizados de la modernidad. En este contexto, no resulta extraño que el cine y las computadoras despunten como objetos privilegiados de indagación, por encima de la televisión y la prensa. Por otra parte, sorprende que en el entorno académico bajacaliforniano, la publicidad, la propaganda, la mercadotecnia, el diseño gráfico, el cartel, la historieta y la fotografía no sean abordados en revistas de investigación arbitradas. Al parecer, estos asuntos son pensados principalmente en revistas de divulgación y otros medios. Es posible, además, que dichos tópicos sean asociados más con la dimensión profesional de nuestro campo, que con la académica. Tampoco existen en las revistas de investigación auscultadas referencias a la historia de los medios de comunicación en Baja California. Una problemática que se dirime sobre todo en libros, capítulos de libros, memorias de congresos y revistas de divulgación. 
Cuadro 10. Artículos de investigación sobre comunicación y cultura en torno a Baja California, por referencia a medios de comunicación y comunicación masiva (1976-2007)

\begin{tabular}{lc}
\hline Referencia & Cantidad \\
\hline Cine & 12 \\
Computadoras, software e Internet & 10 \\
Televisión & 9 \\
Prensa y periodismo & 8 \\
Comunicación de masas & 4 \\
Industrias culturales y mediáticas & 3 \\
Radio & 2 \\
Video y audiovisual & 1 \\
Museos & 1 \\
\hline
\end{tabular}

El cuadro 11 ilustra las orientaciones temáticas de los artículos aquí registrados con respecto al entorno sociocultural. En este cuadro sobresale un primer grupo de textos comunicacionales relacionados con las identidades y prácticas sociales, las representaciones e imaginarios, y los dominios del discurso. Dichos temas son los más desarrollados por la academia bajacaliforniana. Y es así, porque la frontera que comparten México y Estados Unidos es un complejo surtidor de fenómenos simbólicos e identitarios, muchos de carácter emergente, cuyas dinámicas plantean interrogantes inéditas para las ciencias sociales. Este énfasis también consigna uno de los principios más reconocidos por la tradición sociocientífica acerca de los estudios de la comunicación: la comprensión de los procesos comunicativos como procesos culturales, y viceversa.

Por su parte, el cuadro 12 muestra los trayectos temáticos de los artículos en cuestión, con referencia al contexto sociopolítico. Una esfera casi inexplorada por la academia bajacaliforniana en revistas de investigación. Los escasos trabajos acerca de este asunto se encuentran sobre todo en libros, revistas de divulgación y tesis de licenciatura y posgrado. La mayoría de estos textos pertenecen a José Carlos Lozano y fueron elaborados durante su estancia en El Colef a finales de los años ochenta, y a Manuel Ortiz Marín, profesor-investigador 
Cuadro 11. Artículos de investigación sobre comunicación y cultura en torno a Baja California, por referencia al contexto sociocultural (1976-2007)

Referencia

Cantidad

Identidades y prácticas sociales 25

Representaciones e imaginarios sociales 23

Discurso, código, sentido y significado 19

Divulgación de la ciencia y la cultura

Lenguaje, lengua, oralidad y expresión

Oferta y consumo cultural

Ciudad y cultura urbana

Globalización, multiculturalismo e interculturalidad

Arte, estética y creación

Educación y tecnologías de información

Música

Comunicación interpersonal

Ecosistema y medio ambiente

Cuadro 12. Artículos de investigación sobre comunicación y cultura en torno a Baja California, por referencia al contexto sociopolítico (1976-2007)

Referencia

Cantidad

Estado, política y medios de comunicación 5

Política, cultura y ciudadanía 1

Medios de comunicación y relaciones internacionales $\quad 1$

Opinión pública y democracia

de la UABC en Mexicali. Queda pendiente, en este rubro, incrementar y actualizar el análisis de las relaciones entre medios y procesos electorales en Baja California; promover el examen de las estrategias de comunicación social y las políticas públicas; e incorporar a las revistas de investigación el debate sobre la legislación de medios y el derecho a la información, entre otras agendas importantes. 
La relación entre economía y comunicación es otra línea todavía no emprendida por profesores e investigadores de nuestro estado. Temas como los mercados de la comunicación en la frontera, las trasnacionales de la comunicación y sus impactos económicos en la región, las tecnologías de información y comunicación en las relaciones comerciales, la publicidad y los nuevos mercados, así como las dinámicas de la comunicación institucional y organizacional, entre otros, deberán incorporarse en los próximos años como problemas de investigación sociocientífica, y no sólo como saberes asociados a prácticas profesionales.

En cuanto a los artículos de investigación referidos a determinados actores sociales, el cuadro 13 consigna la inclinación de nuestra academia hacia la problemática de los jóvenes. No obstante, en general, los sujetos específicos son mucho menos estudiados que los procesos y productos de la comunicación. Nuestras agendas de investigación giran principalmente alrededor de los escenarios de interacción, las instituciones y los discursos mediáticos. ¿Y los actores sociales? Es decir, ese ámbito pre-interpretado que es la doxa, o como lo plantea J. B. Thompson (1998), la "hermenéutica de la vida cotidiana" necesaria para la elaboración de una interpretación profunda, todavía no adquiere centralidad en nuestra investigación comunicativa y sociocultural. Como se observa en el cuadro 14, los estudios sobre comunicación en esta entidad son poco antropológicos. Los enfoques

Cuadro 13. Artículos de investigación sobre comunicación y cultura en torno a Baja California, por referencia a actores sociales (1976-2007)

\begin{tabular}{lc}
\hline Referencia & Cantidad \\
\hline Jóvenes & 12 \\
Chicanos & 4 \\
Mujeres & 4 \\
Migrantes & 3 \\
Familias & 2 \\
Indígenas & 1 \\
\hline
\end{tabular}


disciplinarios que sustentan estos artículos se orientan preferentemente hacia los estudios culturales, la sociología de la comunicación y la sociología de la cultura, cuyas fases de análisis privilegian sobre todo lo estructural y lo discursivo.

Dado que el campo académico de la comunicación en Baja California está articulado a las escuelas (a diferencia de otras disciplinas como la antropología, donde existen investigadores, actividades académicas y generación de conocimiento en dicha área, a pesar de que no se ofrece esa licenciatura en la entidad), los enfoques disciplinarios que han predominado entre profesores e investigadores durante las últimas dos décadas se acercan más a las sociologías (normativa, crítica y estructural), a la ciencia política, la psicología social, las humanidades, la semiótica y la administración. En nuestras licenciaturas se lee poco a Clifford Geertz, Marc Augé, Guillermo Bonfil Batalla, Renato Rosaldo, Esteban Krotz y otros antropólogos. Por eso, la etnografía es un recurso relegado en nuestra cultura de investigación, como lo muestra el cuadro 14. En Baja California, los académicos que están incorporando perspectivas antropológicas a la comprensión de los fenómenos comunicacionales se formaron en el ITESO, o bajo la tutela del Programa Cultura de la Universidad de Colima, o hicieron posgrados en antropología.

Cuadro 14. Artículos de investigación sobre comunicación y cultura en torno a Baja California, por referencia a enfoques disciplinarios (1976-2007)

\begin{tabular}{lc}
\hline Referencia & Cantidad \\
\hline Estudios culturales/ estudios de la cultura & 31 \\
Sociología de la comunicación & 24 \\
Sociología de la cultura & 18 \\
Semiótica/ semiología & 7 \\
Lingüística y ciencias del lenguaje & 4 \\
Antropología & 3 \\
Comunicología & 3 \\
Historia e historiografía & 3 \\
Educación y pedagogía & 2 \\
Enfoques multidisciplinarios e interdisciplinarios & 2 \\
\hline
\end{tabular}


Cuadro 15. Artículos de investigación sobre comunicación y cultura en torno a Baja California, por referencia a recursos técnico-metodológicos (1976-2007)

\begin{tabular}{lc}
\hline Referencia & Cantidad \\
\hline Análisis cultural & 27 \\
Análisis descriptivo y comparativo & 23 \\
Análisis documental y bibliohemerográfico & 15 \\
Análisis cuantitativo & 8 \\
Análisis de contenido & 5 \\
Biografía, testimonio e historia oral & 5 \\
Encuesta & 5 \\
Entrevista y grupo de discusión & 5 \\
Estudios de recepción & 4 \\
Análisis cualitativo & 3 \\
Análisis del discurso & 1 \\
Etnografía & 1 \\
Bases de datos & 1 \\
\hline
\end{tabular}

Pero tampoco se han desarrollado las perspectivas del derecho y la educación (a pesar de que en Mexicali, la licenciatura en Comunicación comparte con la de Educación el espacio de la Facultad de Ciencias Humanas). Quizás por ello se explica la pasividad de nuestros estudiantes y profesores ante el debate nacional sobre las reformas legales en materia de medios de comunicación, y la permanente indiferencia hacia los dilemas de la comunicación educativa. No obstante, el recuento exhaustivo que integra este compendio deja ver un saldo muy favorable para el crecimiento y la consolidación de este enclave de saberes.

Por último, el cuadro 15 constata la implementación de los análisis cultural, descriptivo y documental como recursos técnico-metodológicos privilegiados en los artículos de investigación aquí consignados. Sobresalen los enfoques cualitativos sobre los cuantitativos, pero también son cada vez más los trabajos que buscan integrar ambas estrategias en la construcción de sus objetos y en la presentación de los resultados de investigación. 


\section{A manera de conclusión}

Mediante una labor de registro y sistematización hemerográfica, así como de análisis descriptivo, este proyecto se propuso dar cuenta del estado de la investigación académica de la comunicación en y sobre Baja California, a través de artículos publicados en revistas especializadas con arbitraje. Se esbozaron ciertas tendencias y rasgos de composición de nuestro campo académico a partir de las últimas dos décadas, señalando algunas condiciones institucionales y contextuales que incidieron en determinadas orientaciones de investigación y análisis.

Se pudo observar que las premisas y enfoques de carácter teóricometodológicos que han constituido a la comunidad académica de la comunicación en nuestro estado, se inscriben en los paradigmas de las ciencias sociales y las humanidades contemporáneas y, específicamente, en las principales tradiciones anglosajonas y latinoamericanas relacionadas con los estudios sociocientíficos de la comunicación y la cultura. En cuanto a las preocupaciones docentes e investigativas, se constató el paso gradual de la revisión o consulta de autores nacionales y extranjeros durante los años ochenta y noventa, al escrutinio, también, de autores bajacalifornianos en la presente década. Los principales temas de investigación y análisis han girado en torno a los medios y las nuevas tecnologías de información y comunicación. Las identidades, las representaciones sociales y los discursos han sido el objeto de estudio privilegiado en la academia bajacaliforniana. Entre los enfoques disciplinarios, sobresalen los estudios culturales y la sociología de la comunicación y la cultura. Los recursos técnicometodológicos más utilizados en este ámbito han sido, hasta ahora, el análisis cultural, descriptivo y documental.

Asimismo, la cantidad y calidad en la producción de artículos de investigación en la entidad revelan la reorientación y el surgimiento de un importante grupo de profesores cuya actividad académica, anteriormente centrada en la docencia, se transformó en una práctica que hoy incluye la investigación formal. Lo anterior, gracias al impulso de ciertas iniciativas institucionales como la aparición de posgrados y centros de investigación, el desarrollo de proyectos editoriales y la implementación de estímulos a la generación de conocimiento. 
Tanto el catálogo de referencias como su sistematización permitieron arrojar luz, por lo menos parcialmente, sobre algunas formas de cómo se ha establecido nuestro razonamiento comunicacional con relación a paradigmas, modelos y objetos de estudio específicos. Pero el objetivo central de este texto no se agota aquí. Su propósito es que sirva para promover distintas lecturas y preguntas de investigación, otros análisis y nuevas categorías para comprender los contornos cambiantes y emergentes del espacio académico y profesional de la comunicación en Baja California.

\section{Bibliografía}

Cervantes, Cecilia (1994), "Investigación mexicana o sobre México basada en análisis de contenido. Bibliografía preliminar", Comunicación y Sociedad, núm. 20, enero-abril de 1994, Guadalajara, Universidad de Guadalajara, pp. 181-196.

Fuentes Navarro, Raúl (2003), La investigación académica sobre comunicación en México. Sistematización documental, 1995-2001, Guadalajara, ITESO. (1996), La investigación de la comunicación en México, 1986-1994, Guadalajara, ITESO/Universidad de Guadalajara. (1987), La investigación de la comunicación en México, 1956-1984, México, Ediciones de Comunicación.

Galindo, Jesús, Tanius Karam y Martha Rizo (2005), Cien libros hacia una comunicología posible, México, Universidad Autónoma de la Ciudad de México.

Gómez Vargas, Héctor (1998), “El campo académico de la comunicación y las reflexividades regionales", Estudios sobre las Culturas Contemporáneas, época II, vol. IV, núm. 8, diciembre de 1998, Colima, Universidad de Colima, pp. 9-34.

Lozano, José Carlos (ed.) (2005), La comunicación en México; diagnósticos, balances y retos, México, Coneicc/Tecnológico de Monterrey.

Sánchez Ruiz, Enrique (1992), Tendencias en la investigación sobre televisión en México, 1950-1990, Guadalajara, Universidad de Guadalajara. 
Thompson, John B. (1998), Ideología y cultura moderna, México, UAMXochimilco.

Vizcarra, Fernando (2007), "Estudios sobre comunicación en Baja California. Tendencias de investigación y análisis, 1943-2005", en revista electrónica Global Media Journal en Español, vol. 4, núm. 7, primavera 2007, ITESM, Campus Monterrey (www.gmje.mty. itesm.mx/vizcarra_fernando.html).

(2006), "Estudios sobre comunicación en Baja California. Tendencias de investigación y análisis, 1943-2004", en Everardo Garduño (coord.), Cultura, agentes y representaciones sociales en Baja California, México, Porrúa/UABC, 2006, pp. 53-70.

Recibido en abril de 2008 Aprobado en agosto de 2008 


\section{Anexo \\ Artículos de investigación sobre comunicación y cultura en Baja California, 1976-2007. Un compendio razonado}

1.

BECERRA VILLEGAS, Jesús

"La subsunción simbólica", en Culturales, Vol. 3, núm. 6, julio-diciembre de 2007, Universidad Autónoma de Baja California, Mexicali, pp. 7-26.

2.

BECERRA VILLEGAS, Jesús

"Creencia narrativa y ciencia positiva", en Utopía y Praxis Latinoamericana, Año 11, núm. 32, enero-marzo de 2006, Universidad del Zulia, Maracaibo, pp. 77-92.

3.

BECERRA VILLEGAS, Jesús

"Culturas de pantalla y violencia simbólica", en Quórum Académico, núm.2, Vol. II, julio-diciembre de 2005, Universidad del Zulia, Maracaibo, pp. 89-103.

4.

BECERRA VILLEGAS, Jesús

"Los medios de la globalización", en revista electrónica Razón y Palabra, núm. 37, febrero-marzo de 2004, Instituto Tecnológico de Estudios Superiores de Monterrey, Campus Estado de México.

http://www.razonypalabra.org.mx/anteriores/n37/jbecerra.html

5 .

BECERRA VILLEGAS, Jesús

"La comunicación: de objeto a categoría", en Estudios sobre las Culturas Contemporáneas, época II, Vol. X, núm. 19, junio de 2004, Programa Cultura/ Universidad de Colima, Colima, pp. 53-65.

6.

BECERRA VILLEGAS, Jesús

"Apropiación, cultura y mediaciones", en Quórum Académico, Vol. 1 núm. 1, enero-junio de 2004, Universidad del Zulia, Maracaibo, pp. 45-62. 
7.

BECERRA VILLEGAS, Jesús

"El lenguaje y el ser: la naturaleza de las culturas desde una perspectiva fronteriza" (reedición), en revista electrónica Hipertextos, núm. 5, 2003, Instituto Tecnológico de Estudios Superiores de Monterrey, Campus Monterrey.

http:/ / hiper-textos.mty.itesm.mx/ becerranum5.htm

8.

BECERRA VILLEGAS, Jesús

"Registro poligráfico de proxémica corporal y temática", en Anuario de Investigación de la Comunicación Coneicc, núm. 6, 2000, Universidad Iberoamericana, Coneicc, Instituto Tecnológico de Estudios Superiores de Monterrey, México, pp. 13-18.

9.

BECERRA VILLEGAS, Jesús

"El lenguaje y el ser: la naturaleza de las culturas desde una perspectiva fronteriza”, revista electrónica Speculum, Vol. I, núm. 1, 2000, Universidad Autónoma de Baja California, Tijuana.

http://www.uabc.mx/humanidades/speculum/volino1/becerra.htm

10.

BECERRA VILLEGAS, Jesús

"Notas para una semiótica del mundo como relato", en Estudios sobre las Culturas Contemporáneas, época II, Vol. 2, núm. 4, diciembre de 1996, Programa Cultura/ Universidad de Colima, Colima, pp. 151-165.

11.

BECERRA VILLEGAS, Jesús

"Tecnología del lenguaje", en Estudios sobre las Culturas Contemporáneas, Vol. V, núm. 15, marzo de 1993, Programa Cultura/ Universidad de Colima, Colima, pp. 227-281.

12.

CROVI DRUETTA, Delia, Soledad Robina Bustos y Florence Toussaint Alcaraz "La frontera y la televisión", en Anuario de Investigación de la Comunicación Coneicc, núm. 3, 1996, Coneicc, Universidad de Guadalajara, México, pp. 187196.

13.

FOGLIO ALMADA, Omar

"Formación de agentes y prácticas de cultura en la vida cotidiana: rock en Tijuana", en revista electrónica Razón y Palabra, primera edición especial, julio 
de 1997, Instituto Tecnológico de Estudios Superiores de Monterrey, Campus Estado de México. www.razonypalabra.org.mx/mcluhan/mcluhan.html.

14.

GAVALDÓN, Lourdes

“Bilingüismo y desplazamiento del español. Notas sobre el caso Tijuana B. CFA.", en Estudios Fronterizos, año 1, núm. 1, mayo-agosto de 1983, Universidad Autónoma de Baja California, Mexicali, pp. 65-74.

15. GONZÁLEZ HERNÁNDEZ, David

"Medios, interacción y audiencia", en revista electrónica Razón y Palabra, núm. 57, junio-julio de 2007, Instituto Tecnológico de Estudios Superiores de Monterrey, Campus Estado de México. www.razonypalabra.org.mx/anteriores/n57/index.html.

16.

GONZÁLEZ HERNÁNDEZ, David, Gerardo León y Ángela Serrano "La formación en Comunicación en Tijuana: apuntes sobre un modelo de plan de estudios de la licenciatura en Comunicación de la UABC, Tijuana", en Anuario de Investigación de la Comunicación Coneicc, núm. 13, 2006, Coneicc, Universidad de Anáhuac, Universidad Iberoamericana, México, pp. 429-441.

17.

GONZÁLEZ HERNÁNDEZ, David

"En busca del entretenimiento: televisión y audiencia juvenil en la frontera norte", en Comunicación y Sociedad, nueva época, núm. 5, enero-junio de 2006, Universidad de Guadalajara, Guadalajara, pp. 157-179.

18.

\section{GONZÁLEZ HERNÁNDEZ, David}

"Vetas de investigación: análisis de televisión e interculturales de recepción en la frontera norte", en Anuario de Investigación de la Comunicación Coneicc, núm. 12, 2005, Coneicc, San Luis Potosí, pp. 219-223.

19.

GONZÁLEZ HERNÁNDEZ, David

"Diálogos entre dos re-establecimientos teóricos-metodológicos: las propuestas de John B. Thompson y Klaus B. Jensen", en Anuario de Investigación de la Comunicación Coneicc, núm. 9, 2003, Coneicc, México, pp. 172-193. 
20.

GONZÁLEZ HERNÁNDEZ, David

"Las materias dispuestas: campo educativo, formación docente y familia", en revista electrónica Razón y Palabra, edición especial, julio de 1997, Instituto Tecnológico de Estudios Superiores de Monterrey, Campus Estado de México. http:/ /www.cem.itesm.mx/dacs/publicaciones/logos/mcluhan/materias.htm

21.

IGLESIAS PRIETO, Norma

"Gazes and Cinematic Readings of Gender, Danzón and its Relation to its Audiences", en Discourses, 26.1 \& 2, Winter and Spring 2004, Wayne State University Press, Detroit, pp. 173-193.

22.

IGLESIAS PRIETO, Norma

"En pocas palabras: representaciones discursivas de la frontera México-Estados Unidos", en Aztlán: A Journal of Chicano Studies, Vol. 29, núm. 1, Spring 2004, Chicano Studies Research Center (CSRC), University of California Los Angeles, Los Ángeles, pp. 145-153.

23.

IGLESIAS PRIETO, Norma

"Rappresentazioni della frontiera Messico-Stati Uniti nel cinema di frontiera", en La Critica Sociologica, núm. 146, septiembre de 2003, SIARES/ Fabrizio Serra Editor, Roma, pp. 25-38.

24.

IGLESIAS PRIETO, Norma

"Reconstruyendo lo femenino: identidades de género y recepción cinematográfica", en Frontera Norte, Vol. 9, núm. 18, julio-diciembre de 1997, El Colegio de la Frontera Norte, Tijuana, pp. 45-62.

25.

IGLESIAS PRIETO, Norma

"El placer de la mirada femenina. Género y recepción cinematográfica", en Frontera Norte, Vol. 6, núm. 12, julio-diciembre de 1994, El Colegio de la Frontera Norte, Tijuana, pp. 93-110.

26.

IGLESIAS PRIETO, Norma

"La producción del cine fronterizo. Una industria de sueño", en Estudios sobre las Culturas Contemporáneas, Vol. IV, núm. 11, Programa Cultura/ Universidad de Colima, Colima, 1991, pp. 97-130. 
27.

LEÓN BARRIOS, Gerardo Guillermo

"Huellas de la incertidumbre en la frontera: migración juvenil en Tijuana", en Periferia, núm. 7, noviembre-diciembre de 2006, Facultad de Ciencias Sociales y Humanas, Universidad Surcolombiana, Bogotá, 2006, pp. 89-97.

\section{8.}

LEÓN BARRIOS, Gerardo Guillermo

"El grupo de discusión como artefacto científico para el análisis social", en revista electrónica Razón y Palabra, núm. 57, junio-julio de 2007, Instituto Tecnológico de Estudios Superiores de Monterrey, Campus Estado de México. www.razonypalabra.org.mx/anteriores/n57/gleon.html

29.

LEÓN BARRIOS, Gerardo Guillermo

"Habitar el mundo: ciudadanía cultural y migración juvenil. Notas para una discusión desde la cultura", en Texto Abierto, Año IV, núm. 6, 2005, Universidad Iberoamericana León, León, pp. 175-188

30.

LÓPEZ ORNELAS, Maricela

"La cibermetría, una nueva alternativa para evaluar la visibilidad de la publicación académica electrónica. El caso de la REDIE", en revista electrónica Razón y Palabra, núm. 58, agosto-septiembre de 2007, Instituto Tecnológico de Estudios Superiores de Monterrey, Campus Estado de México.

http://www.cem.itesm.mx/dacs/publicaciones/logos/actual/mlopez.html

31.

LÓPEZ ORNELAS, Maricela

"Las revistas académicas electrónicas en México. Un camino para resistir o desistir ante el reconocimiento del Consejo Nacional de Ciencia y Tecnología", en revista electrónica Razón y Palabra, núm. 52, agosto-septiembre de 2006, Instituto Tecnológico de Estudios Superiores de Monterrey, Campus Estado de México. http://www.cem.itesm.mx/dacs/publicaciones/logos/anteriores/n52/mlopez.html

\section{2.}

LÓPEZ ORNELAS, Maricela

“Confiabilidad y prestigio en las publicaciones electrónicas, un sólo camino: la evaluación", en Revista Latina de Comunicación Social, núm. 60, julio-diciembre de 2005, Universidad de La Laguna, Tenerife.

http:/ / www.ull.es/publicaciones/latina/revistaweblopezornelas.htm 
33.

LÓPEZ ORNELAS, Maricela, Graciela Cordero Arroyo y Eduardo Backhoff "Measuring the Quality of Electronic Journals", en Electronic Journal of Information Systems Evaluation, Vol. 8 (2), july 2005, Academic Conferences Limited, England.

http://www.ejise.com/volume-8/v8-iss-2/v8-i2-art6-lopez.pdf

34.

LÓPEZ ORNELAS, Maricela y Graciela Cordero Arroyo

"Un intento por definir las características generales de las revistas académicas electrónicas", en revista electrónica Razón y Palabra, núm. 43, febrero-marzo de 2005, Instituto Tecnológico de Estudios Superiores de Monterrey, Campus Estado de México. http://www.razonypalabra.org.mx/libros/libros/ caracrevelec.pdf

35.

LÓPEZ ORNELAS, Maricela, Graciela Cordero Arroyo, Javier Organista Sandoval y Kiyoko Nishikawa Aceves

“Revista impresa o electrónica. ¿Cuál es la alternativa? El caso de la Revista de Investigación Educativa (REDIE) “, en revista electrónica Pixel-Bit, Revista de Medios y Educación, núm. 25, enero de 2005, Universidad de Sevilla, Sevilla. http://redalyc.uaemex.mx/redalyc/pdf/368/36802503.pdf

36.

LÓPEZ ORNELAS, Maricela y Graciela Cordero Arroyo

"La experiencia de validar un instrumento para evaluar revistas académicas electrónicas", en revista electrónica Razón y Palabra, núm. 31, febrero-marzo de 2003, Instituto Tecnológico de Estudios Superiores de Monterrey, Campus Estado de México. http://www.razonypalabra.org.mx/anteriores/n31/mlopez.html

37.

LOZANO RENDÓN, José Carlos

"Del imperialismo cultural a la audiencia activa: aportes teóricos recientes", en Comunicación y Sociedad, núm. 10-11, septiembre de 1990-abril de 1991, Universidad de Guadalajara, Guadalajara, pp. 85-106.

38.

LOZANO RENDÓN, José Carlos

"Enfoques teóricos para el estudio de la cultura en la frontera de México con los Estados Unidos", en Río Bravo, a Bilingual Journal of International Studies, Vol. I, núm. 1, otoño de 1991, The University of Texas-Pan American, Edinburg, pp. 27-46. 
39.

LOZANO RENDÓN, José Carlos

"Identidad cultural, actitudes políticas y valores socioculturales en Tijuana, Ciudad Juárez, Nuevo Laredo y San Luis Potosí", en Estudios Fronterizos, núm. 22, mayo-agosto de 1990, Universidad Autónoma de Baja California, Mexicali, pp. 59-80.

40.

\section{LOZANO RENDÓN, José Carlos}

"Imágenes de México en la prensa norteamericana: análisis comparativo de la cobertura de México en Times y Newsweek de 1980 a 1986", en Comunicación y Sociedad, núm. 7, septiembre-diciembre de 1989, Universidad de Guadalajara, Guadalajara, pp. 77-102.

\section{1.}

LOZANO RENDÓN, José Carlos

"Issues and Sources in Spanish-language TV: A Comparison of Noticiero Univisión and NBC Evening News", en Frontera Norte, Vol. I, núm. 1, enerojunio de 1989, El Colegio de la Frontera Norte, Tijuana, pp. 151-173.

\section{2.}

\section{MÉNDEZ FIERROS, Hugo}

"Representaciones mediáticas del agua, el clima y la energía eléctrica en zonas áridas. El caso de Mexicali, B. C.", en Culturales, Vol. 3, núm. 6, juliodiciembre de 2007, Universidad Autónoma de Baja California, Mexicali, pp. 121-146.

43.

MARTÍNEZ LOZANO, Consuelo Patricia

"El esquema cultural de género y sexualidad en la vida cotidiana. Una reflexión teórica", en Culturales, Vol. I, núm. 2, julio-diciembre de 2005, Universidad Autónoma de Baja California, Mexicali, pp. 30-62.

44.

MIXCO, Mauricio J.

"The Linguistic Affiliation of the Nakipa and Yakakwal of Lower California", en International Journal of American Linguistics, Vol. 43, núm. 3, julio de 1977, The University of Chicago, Chicago, pp. 189-200.

45.

MORALES LIRA, Ricardo

"De sujetos, redes y prácticas culturales", en Anuario de Investigación de la Comunicación Coneicc, núm. 8, 2001, Coneicc, México, pp. 139-152. 
46.

MORALES LIRA, Ricardo

"La juventud como imagen", en Texto Abierto, año 1, núm. 1, 2001, Universidad Iberoamericana León, León, pp. 139-151.

47.

MORALES LIRA, Ricardo

"Cultura tecnológica. Los avatares de los maestros del Programa Nacional de Educación a Distancia", en Anuario de Investigación de la Comunicación Coneicc, núm. 6, 2000, Universidad Iberoamericana, Coneicc, Instituto Tecnológico de Monterrey, México, pp. 175-180.

48.

MORALES LIRA, Ricardo

"Rutas laborales y conexión tecnológica. Biografía tecnológica de Raúl Garza y Treviño", en Anuario de Investigación de la Comunicación Coneicc, núm. 6, 2000, Universidad Iberoamericana, Coneicc, Instituto Tecnológico de Monterrey, México, pp. 181-190.

49.

MORALES LIRA, Ricardo

"La juventud como imagen", en Espacios de la Comunicación, núm. 4, 2000, Universidad Iberoamericana, México, pp. 373-384.

50.

MORALES LIRA, Ricardo

"De redes, creadores y sujetos otros: las redes de comunicación y cultura en los jóvenes", en Espacios de la Comunicación, núm. 2, 1998, Universidad Iberoamericana, México, pp. 237-246.

51.

MORALES LIRA, Ricardo

"El filin de la vida. Cultura, comunicación y cotidianidad urbana", en Espacios de la Comunicación, núm. 3, 1998, Universidad Iberoamericana, México, pp. 285-300.

52.

MORALES LIRA, Ricardo

“De redes, creadores y sujetos otros. Las redes de comunicación y cultura en los jóvenes", en revista electrónica Razón y Palabra, primera edición especial, julio de 1997, Instituto Tecnológico de Estudios Superiores de Monterrey, Campus Estado de México. http://www.razonypalabra.org.mx/mcluhan/ mcluhan.html 
53.

MORALES LIRA, Ricardo y Alfonso García Cortéz

"La Revolución también es una calle. De frentes, fronteras y cruces culturales", en Estudios sobre las Culturas Contemporáneas, Época II, Vol. 1, núm. 2, diciembre de 1995, Programa Cultura, Universidad de Colima, Colima, pp. 9-32.

54.

MURÍA, Magali y Teófilo Chávez

“¿Cómo vemos a nuestros vecinos del norte? Apuntes sobre la representación de San Diego en la prensa de Tijuana", en Comunicación y Sociedad, nueva época, núm. 6, julio-diciembre de 2006, Universidad de Guadalajara, Guadalajara, pp. 37-57.

\section{5.}

NISHIKAWA ACEVES, Kiyoko

"La difusión vía Internet del conocimiento sobre educación en México. Estudio de la primera generación de revistas electrónicas de educación", en revista electrónica Zer, Revista de Estudios de Comunicación, núm. 14, mayo de 2003, Universidad del País Vasco, Bilbao. www.ehu.es/zer/zer14/difusion14.htm.

56.

NISHIKAWA ACEVES, Kiyoko

"La oralidad como acercamiento a las identidades culturales en la vida familiar", en Espacios de la Comunicación, núm. 4, 2000, Universidad Iberoamericana, México, pp. 283-296.

57.

ORTEGA VILLA, Luz María.

"Uso de métodos cualitativos y cuantitativos en el estudio del consumo de bienes culturales en sectores populares de Mexicali, B. C.", en Estudios fronterizos, nueva época, Vol. 8, núm. 16, julio-diciembre 2007, Universidad Autónoma de Baja California, Mexicali, pp. 43-63.

58.

ORTEGA VILLA, Luz María

"Tipología del consumo de bienes culturales en Mexicali, B. C.", en Frontera Norte, núm. 36, julio-diciembre de 2006, El Colegio de la Frontera Norte, Tijuana, pp. 53-85.

59.

ORTEGA VILLA, Luz María

"El conocimiento de la función extensión por parte de sus trabajadores en la UABC", en Revista de la Educación Superior, Vol. XXXII (2), núm. 126, abril-junio de 2003, ANUIES, México, pp. 25-39. 
60.

ORTEGA VILLA, Luz María

“De los puentes para los campos. Reflexiones en torno a la divulgación de la ciencia", en revista electrónica Razón y Palabra, núm. 32, abril-mayo de 2003, Instituto Tecnológico de Estudios Superiores de Monterrey, Campus Estado de México. http://www.razonypalabra.org.mx

61.

ORTIZ MARÍN, Manuel

"Las fronteras entre poder, Estado y medios de comunicación masiva desde la teoría crítica", en Estudios Fronterizos, nueva época, Vol. 7, núm. 14, julio-diciembre de 2006, Universidad Autónoma de Baja California, Mexicali, pp. 9-31.

62.

ORTIZ MARÍN, Manuel

"La interdependencia estructural entre el Estado y la prensa en Baja California", en Question, núm. 10, mayo de 2006, Facultad de Periodismo y Comunicación Social, Universidad de La Plata, Buenos Aires.

63.

ORTIZ MARÍN, Manuel

"La comunicación social en Baja California. La mediación entre el Estado y la prensa (1989-1995)", en Anuario de Investigación de la Comunicación Coneicc, núm. 6, 2000, Universidad Iberoamericana, Coneicc, Instituto Tecnológico de Estudios Superiores de Monterrey, México, pp. 139-152.

64.

ORTIZ MARÍN, Manuel

"La radio universitaria en la $\mathrm{UABC}$, en Revista de la Educación Superior, núm. 103, julio-septiembre de 1997, ANUIES, México, pp. 129-143.

65.

ORTIZ MARÍN, Manuel, Felipe Guicho y otros

"Cobertura informativa en la prensa regional mexicana", en Anuario de Investigación de la Comunicación Coneicc, núm. 2, 1995, Coneicc, México, pp. 241-259.

66.

OVALLE, Lilian Paola

"Entre la indiferencia y la satanización. Representaciones sociales del narcotráfico desde la perspectiva de los universitarios de Tijuana", en Culturales, Vol. I, núm. 2, julio-diciembre de 2005, Universidad Autónoma de Baja California, Mexicali, pp. 63-89. 
67.

PÉREZ ORDUÑA, Nora E.

"Un viaje en familia: historia oral y genealogías culturales", en revista electrónica Razón y Palabra, primera edición especial, julio de 1997, Instituto Tecnológico de Estudios Superiores de Monterrey, Campus Estado de México.

http://www.razonypalabra.org.mx/mcluhan/mcluhan.html

68.

RODRÍGUEZ SALA, Ma. Luisa

"Identidad cultural en grupos sociales de la zona fronteriza de Baja California", en Estudios Fronterizos, año III, núm. 7-8, mayo-agosto/ septiembre-diciembre de 1985, Universidad Autónoma de Baja California, Mexicali, pp. 69-83.

69.

RODRÍGUEZ SALA DE GÓMEZGIL, Ma. Luisa

"El lenguaje como elemento cultural de identidad social en la zona fronteriza", en Estudios Fronterizos, año 1, núm. 2, septiembre-diciembre de 1983, Universidad Autónoma de Baja California, Mexicali, pp. 153-164.

70.

SAMANIEGO LÓPEZ, Marco Antonio

"Prensa y filibusterismo en los sucesos de 1911", en Estudios Fronterizos, núm. 33, enero-junio de 1994, Universidad Autónoma de Baja California, Mexicali, pp. 125-155.

71.

SÁNCHEZ VÁZQUEZ, María Alejandra

"The Trouble with Boredom: Contextualising the Disposition, Analysing its Potential", en Culturales, Vol. III, núm. 5, enero-junio de 2007, Universidad Autónoma de Baja California, Mexicali, pp. 43-78.

72.

TOUDERT, Djamel

"La WWW en la frontera mexicana. Hacia el descubrimiento de una dimensión desconocida", en Frontera Norte, Vol. 13, núm. 24, julio-diciembre de 2000, El Colegio de la Frontera Norte, Tijuana, pp. 7-33.

73.

TOUSSAINT, Florence y Raúl Navarro

"Frontera Norte: estructura de poder y medios de comunicación", en Estudios sobre las Culturas Contemporáneas, Vol. IV, núm. 11, marzo de 1991, Programa Cultura/ Universidad de Colima, Colima, pp. 131-168. 
74.

TRUJILLO MUÑOZ, Gabriel

"Cine eres y en cine te convertirás", en Estudios sobre las Culturas Contemporáneas, época II, Vol. 2, núm. 4, diciembre de 1996, Programa Cultura/ Universidad de Colima, Colima. pp. 125-136.

75.

VALENZUELA ARCE, José Manuel

"Fronteras y representaciones sociales: la figura del pocho como estereotipo del chicano", en Aztlán: A Journal of Chicano Studies, Vol. 29, núm. 1, Spring 2004, Universidad de California, Los Ángeles, pp. 125-133.

76.

VALENZUELA ARCE, José Manuel y Fiamma Montezemolo

"Nortec: il movimento elettronico a Tijuana", en La Critica Sociologica, núm. 146, septiembre de 2003, SIARES/ Fabrizio Serra Editor, Roma, pp. 39-48.

77.

VALENZUELA ARCE, José Manuel

"Al otro lado de la línea. Representaciones socioculturales en las narrativas sobre la frontera México-Estados Unidos", en Revista Mexicana de Sociología, año LXII, núm. 2, abril-junio de 2000, Universidad Nacional Autónoma de México, México, pp. 125-149.

78.

VALENZUELA ARCE, José Manuel

"Norteños ayankados. Discursos y representaciones de la frontera", en Comunicación y Sociedad, núm. 38, julio-diciembre de 2000, Universidad de Guadalajara, Guadalajara, pp. 37-57.

79.

VALENZUELA ARCE, José Manuel

"Las identidades culturales frente al TLC", en Sociológica, año 8, núm. 21, enero-abril de 1993, Universidad Autónoma Metropolitana-Azcapotzalco, México, pp. 103-129.

80.

VALENZUELA ARCE, José Manuel

"Permanencia y cambio de las identidades étnicas: la población de origen mexicano en Estados Unidos", en Estudios Sociológicos, Vol. X, núm. 28, eneroabril de 1992, El Colegio de México, México. 
81.

VALENZUELA ARCE, José Manuel

"Racismo y resistencia cultural: la población de origen mexicano en Estados Unidos", en Eslabones, núm. 4, julio-diciembre de 1992, Universidad de Guadalajara, Guadalajara, pp. 122-128.

\section{2.}

VALENZUELA ARCE, José Manuel

"Modernidad, postmodernidad y juventud", en Revista Mexicana de Sociología, Vol. LIII, núm. 1, enero-marzo de 1991, Universidad Nacional Autónoma de México, México, pp. 167-202.

83.

VIZCARRA, Fernando

"Estudios sobre comunicación en Baja California. Tendencias de investigación y análisis 1943-2005", en revista electrónica Global Media Journal en Español, Vol. 4, núm. 7, primavera 2007, Instituto Tecnológico de Estudios Superiores de Monterrey, Campus Monterrey. www.gmje.mty.itesm.mx/ vizcarra_fernando.html.

84.

VIZCARRA, Fernando

"Coordenadas para una sociología del cine", en Intercultural Communication Studies, Vol. XIV-3, 2006, University of Louisville, San Antonio, pp. 190-199.

85. VIZCARRA, Fernando

"Arte, cine y modernidad. Los orígenes de un nuevo lenguaje", en Texto Abierto, año 4, núm. 6, primavera 2005, Universidad Iberoamericana León, León, pp. 53-88.

86.

VIZCARRA, Fernando

"Opinión pública, medios y globalización. Un retorno a los conceptos", en Culturales, Vol. I, núm. 1, enero-junio de 2005, Universidad Autónoma de Baja California, Mexicali, pp. 57-73.

87.

VIZCARRA, Fernando

"El cine futurista y la memoria del porvenir", en Estudios sobre las Culturas Contemporáneas, época II, Vol. 9, núm. 18, diciembre de 2003, Programa Cultura/ Universidad de Colima, Colima, pp. 87-100. 
88.

VIZCARRA, Fernando

"Premisas y conceptos básicos en la sociología de Pierre Bourdieu", en Estudios sobre las Culturas Contemporáneas, época II, Vol. 8, núm. 16, diciembre de 2002, Programa Cultura/ Universidad de Colima, Colima, pp. 55-67.

89.

VIZCARRA, Fernando

"Lo artístico y lo industrial en la estética del cine. Una propuesta de investigación", en Estudios sobre las Culturas Contemporáneas, época II, Vol. 8, núm. 15, junio de 2002, Programa Cultura/ Universidad de Colima, Colima, pp. 113131.

90.

VIZCARRA, Fernando

"La formación del campo de producción artística contemporáneo y el nacimiento del cine como arte", en Comunicación y Sociedad, núm. 40, julio-diciembre de 2001, Universidad de Guadalajara, Guadalajara, pp. 245-273.

91.

VIZCARRA, Fernando

"Las ciudades nómadas. Notas sobre comunicación y cultura", en Estudios sobre las Culturas Contemporáneas, época II, Vol. 2, núm. 4, diciembre de 1996, Programa Cultura/ Universidad de Colima, Colima, pp. 83-92.

92.

VIZCARRA, Fernando

"Artes, humanidades y comunicación", en Estudios sobre las Culturas Contemporáneas, época II, Vol. I, núm. 2, diciembre de 1995, Programa Cultura/ Universidad de Colima, Colima, pp. 107-116. 